\title{
Effects of Post-Training Blockade of GABAB Receptor on Memory of Food Location and Expression of Synapsin I in the Hippocampus of Pigeons (Columba livia)
}

\author{
Fernando Canova*, Rodolfo Souza Faria, Elenice Aparecida de Moraes Ferrari \\ Laboratory of Neural Systems and Behavior, Department of Structural and Functional Biology, Institute of \\ Biology, State University of Campinas-UNICAMP, Campinas, Brazil \\ Email: ${ }^{*}$ fernando.canova@gmail.com
}

Received 7 October 2014; revised 22 November 2014; accepted 9 December 2014

Copyright (C) 2014 by authors and Scientific Research Publishing Inc.

This work is licensed under the Creative Commons Attribution International License (CC BY). http://creativecommons.org/licenses/by/4.0/

(c) (i) Open Access

\begin{abstract}
This study investigated effects of post-training treatment with phaclofen, GABA $A_{B}$ receptor antagonist, on the memory of food location and on the expression of Synapsin $I$ in the hippocampus of pigeons. Pigeons were trained in food location ( 7 sessions) and underwent post-training treatment with phaclofen $(0.3 \mathrm{mg} / \mathrm{kg}$, i.p.; PHAC), saline (SAL) or non-treated (NTR). Testing for memory persistence occurred 7 days after the last training session (PHACR, SALR and NTRR Groups). Pigeons treated with phaclofen had lower latency and higher correct choice values than saline and non-treated controls $(p<0.05)$. Analysis of hippocampus tissue indicated that Synapsin I-positive cell counts were higher in pigeons treated with phaclofen than in saline and non-treated controls $(p<0.05)$. Data indicated enhancement of consolidation and persistence of food location memory, and up-regulation of Synapsin I expression in the hippocampus of pigeons, which were related with post-training blockade of $\mathrm{GABA}_{B}$ receptors.
\end{abstract}

\section{Keywords}

Spatial Memory, Hippocampus, Synapsin I, GABA $\mathrm{B}_{\mathrm{B}}$ Receptor, Pigeon

\section{Introduction}

Spatial memory involves brain functions responsible for recognizing, codifying, storing and recovering informa-

"Corresponding author.

How to cite this paper: Canova, F., Faria, R.S. and Ferrari, E.A.M. (2014) Effects of Post-Training Blockade of GABA Recep- $^{\circ}$ tor on Memory of Food Location and Expression of Synapsin I in the Hippocampus of Pigeons (Columba livia). Journal of Behavioral and Brain Science, 4, 579-589. http://dx.doi.org/10.4236/jbbs.2014.412055 
tion about the location of particular places or events in the space, the spatial relationships between them, and functions which are fundamental for the survival of the species [1] [2]. Formation and persistence of spatial memory require regulation of multiple intracellular signaling pathways and molecular mechanisms [3].

Most of the knowledge about synaptic mechanisms underlying spatial learning and memory has been essentially related with glutamatergic neurotransmission in the hippocampus [4]. However, it is worth considering the regulatory role played by other neurotransmitters in these mechanisms, particularly the gamma-amino butyric acid (GABA) - a major inhibitory neurotransmitter in the brain. GABA prevents neuronal hyperexcitation, playing a complementary function in the control of signal transduction in the hippocampus [3] [5], the structure essentially involved with the organization of place learning and spatial mapping [1] [2] [6]. The GABAergic neurotransmission, thus, provides a balance between neurotransmitters, which is basic for the regulation of essential mechanisms underlying memory [7].

GABA acts via three major subclasses of membrane receptors: $G_{A B A}$ and $G_{A B A}$ receptors are ligandgated chloride channels whereas $G A B A_{B}$ is metabotropic receptors linked via $G$-proteins to potassium channels. $\mathrm{GABA}_{\mathrm{B}}$ receptors also function as pre-synaptic auto-receptors, inhibiting the release of GABA. GABAergic receptor agonists and antagonists can, respectively, impair and facilitate memory retrieval [5] [8]. Numerous studies show the effects of $\mathrm{GABA}_{A}$ receptor in learning [9], but the role of $\mathrm{GABA}_{B}$ receptor in hippocampus-dependent memory processes, particularly in birds, still needs research. Administration of $G_{A B A}$ receptor antagonists has been linked to increased spatial memory in rodents [10]-[12] and humans [13]. GABA $A_{B}$ receptor antagonists have also been reported to induce up-regulation of Synapsin I expression—one molecule associated with neuroplasticity underlying hippocampus-dependent spatial memory [14] [15]. Deficits in spatial learning have been related with low level of Synapsin I [16]. Synapsin I is involved in neurotransmitter release, axonal elongation, formation and maintenance of synaptic contacts, and is considered as a marker to evaluate synaptic function associated with learning and neuroplasticity [14] [17] [18].

Considering these evidences and the fact that birds with intact hippocampus can solve spatial tasks [2] [19] [20], such as the location of food in a dry version of the Morris maze [21]-[23], we investigated, in pigeons, the effects of the post-training blockade of $\mathrm{GABA}_{\mathrm{B}}$ receptors on both the formation and persistence of spatial memory of food location and on the expression of Synapsin I in the hippocampus.

\section{Material \& Methods}

\subsection{Animals}

Adult male pigeons (Columba livia), age around 24 months, weighing on average $450 \mathrm{~g}$, were used. They were obtained from the pigeon breeding center São Francisco in Limeira, SP, Brazil and were housed in a pigeon vivarium, in individual cages with food and water (mixture of corn grits, sunflower seed and poultry feed), and were maintained at $25^{\circ} \mathrm{C}$, in 12:12 h light-dark cycle (lights on at 06:00 a.m.).

The experimental procedures were approved by the Ethics Committee for Animal Experimentation of the Institute of Biology, UNICAMP, Brazil (Protocol \#2096-1).

Groups of pigeons were treated with Phaclofen (PHAC, $n=14$ ), Saline (SAL, $n=14$ ), or received no-treatment (NTR, $n=14)$. All groups underwent training in location of food. After the end of the $7^{\text {th }}$ session, one half of the pigeons of each group was arbitrarily selected for a testing of memory persistence (R), which was conducted 7 days later (PHACR; $\mathrm{n}=7$; SALR; $\mathrm{n}=7$; NTRR; $\mathrm{n}=7$ ).

\subsection{Procedures}

\subsubsection{Weight Control and Food Deprivation}

Following the period of adaptation, the pigeons underwent daily weighting ( 7 days) for assessment of the average ad libitum weight and the experimental weight. Food deprivation consisted in gradual reduction of the daily food supply, until the experimental weight ( $80 \%$ of the ad libitum weight) was reached ( 7 - 10 days). The birds received ad libitum water during all the experimental period [19].

\subsubsection{Apparatus and Experimental Situation}

Sessions were conducted in a wood circular arena $(1.5 \mathrm{~m}$ diameter $\times 50 \mathrm{~cm}$ height) with white floor and border, positioned in the center of the experimental room $(2.11 \mathrm{~m}$ wide $\times 3.10 \mathrm{~m}$ length $\times 2.77 \mathrm{~m}$ height). The floor was 
covered with a rough brown paper that was changed after each session. One small table $(0.40 \times 100 \times 0.60 \mathrm{~m})$ at left of the entrance door; visual stimuli like sockets, light switches, and pictures $(30 \mathrm{~cm} \times 40 \mathrm{~cm})$ fixed in each wall of the room-red circle, blue square, green triangle or a yellow star-, were used as distal landmarks. Four points equally spaced along the arena circumference were defined as N (north), E (east), S (south) and W (west). They served as orientation points every time the pigeon was placed inside the chamber. The arena area was also virtually divided into four equal sized quadrants (NE, SE, SW and NW) [19] [22] [23]. In the SW quadrant there was a cup filled with food and covered with sand whereas in the other three quadrants identical cups were filled with plain sand. Sessions were recorded with a digital recording camera (Seykon, Mod. SK 1710-c) located 2.60 $\mathrm{m}$ above the center of the arena, which was connected to a monitor and computer system located in an adjoining room.

\subsubsection{Habituation to the Experimental Situation}

Four days preceding the beginning of the experimental sessions, the pigeons were handled at the time scheduled for experiment (8:00 to 12:00 a.m.) [24]. Two days before the first training, they had two 10 min exposures to the arena, with a 5 min interval between them (habituation to the arena). No food cups were present in the experimental arena.

\subsubsection{Drugs}

The phaclofen (P118-Sigma-Aldrich, USA) was diluted in 0.9\% saline and administered intraperitoneally (i.p., $0.3 \mathrm{mg} / \mathrm{kg}$ ) [5] immediately after the end of each training session of the pigeons in the PHAC group. Pigeons of the SAL group received i.p. administration of saline immediately following the end of each training session. Pigeons NTR group received no treatment with phaclofen or saline.

\subsubsection{Training in Spatial Location of Food}

Training was conducted during seven sessions, each one with six trials. The location of the correct food cup remained fixed during all the six trials - in the center of SW quadrant, $18 \mathrm{~cm}$ from the arena wall, but in each trial the bird was liberated at a different starting point [2] [22] [23]. The pigeons were gently placed in the arena with its head facing the wall of the arena. The lights and a digital chronometer were simultaneously turned on and the time until the first pecking in one of the food cups (latency) and the accuracy of the choice were recorded. The choice was rated as correct if the pigeon pecked the cup containing food, as error if the pigeon first pecked a cup with plain sand and as omission if no choice response occurred during the 5 min trial. After a correct choice the pigeons were allowed access to the food during $5 \mathrm{~s}$. The end of the trial was signaled by lights off that occurred after this feeding period, one wrong choice or one omission of choice [19]. During the intertrial intervals (3 min), the pigeon stayed in a cage located in an adjacent room. In the first training session three grains of food were left on the top of the correct cup during the first two trials. The latency and accuracy of choice values were further validated through the transcription of the digital recording of the sessions.

\subsubsection{Testing of Spatial Memory Persistence}

This test consisted of one experimental session of spatial location of food which was conducted 7 days after the final $\left(7^{\text {th }}\right.$ session) training session. The procedures were the same as those used during training, but no treatment was undertaken after this session [19].

\subsubsection{Immunohistochemistry Analysis of Hippocampus Tissue}

After 60 min since the end of the $7^{\text {th }}$ experimental session (PHAC, SAL and NTR groups), or of the testing session of memory persistence (PHACR, SALR and NTRR), the birds were anesthetized with ketamine ( $2 \mathrm{mg} / \mathrm{kg}$, i.m.) and xylazine (5 mg/kg, i.m.) and underwent cardiac perfusion with $0.9 \%$ saline and $4 \%$ paraformaldehyde (PFA) in $0.1 \mathrm{M}$ phosphate buffer (PB, pH 7.4). The brains were post-fixed in 4\% PFA during a 4 - $6 \mathrm{~h}$ period and subsequently stored in a $30 \%$ sucrose solution at $4{ }^{\circ} \mathrm{C}$ for at least $48 \mathrm{~h}$. The brains were sectioned (30 $\left.\mu \mathrm{m}\right)$ on a sliding microtome in the coronal plane. Sections were incubated with the primary antibody (rabbit polyclonal antibody) against the Synapsin I protein (ab64581; ABCAM Cambridge, United Kingdom) diluted 1:1000 in PB containing $0.3 \%$ Triton $\mathrm{X}-100$, during 12 - $16 \mathrm{~h}$ at $22^{\circ} \mathrm{C}$. Following three 10 -min washes in PB, the sections were incubated with a biotinylated goat anti-rabbit serum (Jackson Laboratories, USA) diluted 1:200 in PB with 
$0.3 \%$ Triton $\mathrm{X}-100$ at $22^{\circ} \mathrm{C}$ for $1 \mathrm{~h}$. Finally, the sections were incubated for $2 \mathrm{~h}$ with the avidin-biotin-peroxidase complex (ABC Elite Kit; Vector Labs, USA). Following, the sections were treated with $0.05 \%$ 3.3'-diaminobenzidine solution with $3 \mu \mathrm{L} 0.01 \% \mathrm{H}_{2} \mathrm{O}_{2}$ for $5 \mathrm{~min}$. The sections were mounted on gelatin coated glass slides, dehydrated in an ethanol series, and over slipped with Permount (Fisher, USA). Sections from both brain hemispheres were examined under a light microscope. The immunoreactive cells were quantitated with the Image $\mathrm{J}$ software (NIH Image). The count was reported as the density of Synapsin I protein cells (cells $/ \mathrm{mm}^{2}$ ). A minimum of 5 sections from each subject were examined. According to previous studies [25] our analysis was conducted in the hippocampus [6] [26], considering the division which in a dorsal region (DHp) and in ventral region (VHp). These divisions were roughly corresponding to the dorsomedial region and the medial V-complex region.

\subsubsection{Statistical Analysis}

ANOVA for repeated measures considering the factor group (PHAC, SAL, NTR) and session (S1-S7) as repeated measure was run for comparisons of the mean values of the choice latency and the accuracy index. Twoway ANOVA was used for comparisons of values of the latency and accuracy index of the $7^{\text {th }}$ training session (final training) and the testing session for the groups NTRR, SALR and PHACR. Tukey-Kramer test was used for post-hoc multiple comparisons. Comparisons of Synapsin I-positive cells counting used one-way ANOVA when total hippocampus counting was considered. Two-way ANOVA was used for comparisons of Synapsin Ipositive cells counting in different regions of the hippocampus, using group (NTR, SAL, PHAC, NTRR, SALR and PHACR) and region of the hippocampus (DHp or VHp) as factors. The Tukey-Kramer test was used for post-hoc multiple comparisons. The statistical significance level was set at $p \leq 0.05$.

\section{Results}

Figure 1 presents (Top) the mean percent latency of the choice response across training sessions for the PHAC,
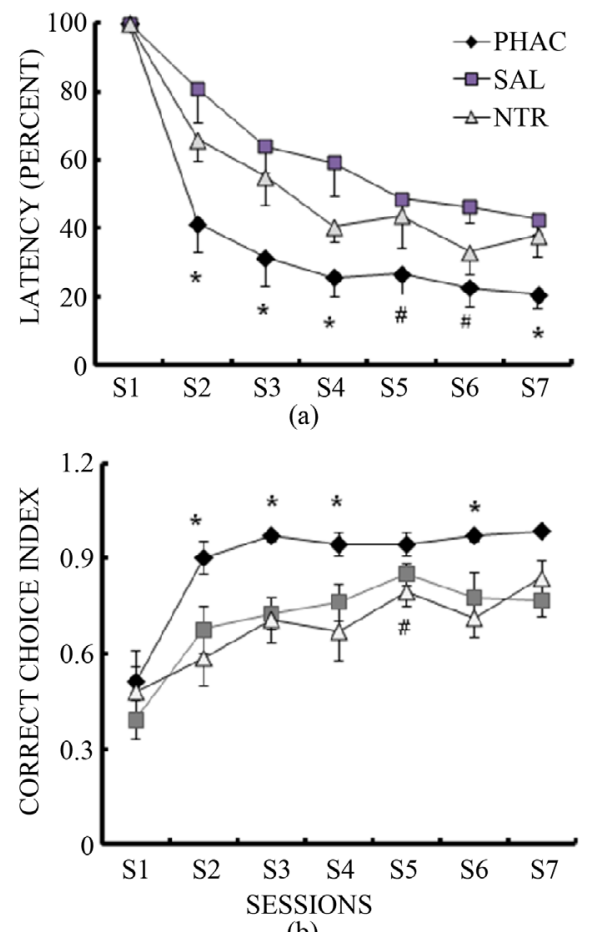

(b)

Figure 1. (a) Percent mean ( \pm s.e.m) latency (sec) of the feeder choice across the sessions of training. Each value was calculated relative to the $1^{\text {st }}$ session. *Significantly different from SAL and NTR groups; ${ }^{\text {\# }}$ Significant difference between PHAC and SAL groups (Tukey-Kramer, $p<0.05$ ); (b) Mean ( \pm s.e.m) values of the index of correct choices, calculated for the six trials in each session of NTR, SAL and PHAC groups. "Significantly different from SAL and NTR groups; "Significant difference between PHAC and SAL groups (Tukey-Kramer, $p<0.05$ ). 
SAL and NTR groups. Each value was calculated for each session relative to the mean latency in the first session (100\%). ANOVA indicated statistically significant differences between groups $\left(F_{2,36}=35.16, p<0.001\right)$, session $\left(F_{6,36}=66.51 ; p<0.001\right)$, and a significant interaction between group and session $\left(F_{2,6}=1.87 ; p<0.05\right)$. The latencies in the $2^{\text {nd }}, 3^{\text {rd }}, 4^{\text {th }}$ and $7^{\text {th }}$ sessions of the PHAC group were significantly different from those in NTR and SAL groups, and in the $5^{\text {th }}$ session of SAL group $(p<0.05)$. The mean $( \pm$ s.e.m) values of correct choices index (Bottom) increased across the sessions of NTR, SAL and PHAC groups. Analysis with ANOVA indicated that the correct choice index differed significantly between groups $\left(\mathrm{F}_{2,36}=32.46 ; p<0.001\right)$ and between sessions $\left(\mathrm{F}_{6,36}=24.01 ; p<0.001\right)$. Multiple post hoc comparisons indicated that the correct choice index values in the session 1 was significantly different from the other six sessions of training and that the PHAC group differed significantly from NTR and SAL groups in the $2^{\text {nd }}, 3^{\text {rd }}, 4^{\text {th }}$ and $6^{\text {th }}$ sessions $(p<0.05)$.

Figure 2 shows the performance of the birds PHACR, SALR and NTRR in the $7^{\text {th }}$ session of training in spatial food location (final training) and in the testing of the persistence of memory (test) conducted 7 days after the final training. The percent values were calculated relative to the mean values of the first training session (100\%). The data show that the PHACR group had latency values that were lower than those of the groups SALR and NTRR in both during the final training and in the test (Top panel). These group differences in latency values were confirmed by ANOVA $\left(\mathrm{F}_{2,15}=12.17 ; p<0.001\right)$ and the Tukey-Kramer multiple comparisons indicated that the PHACR group was different form both SALR and NTRR groups $(p<0.05)$. The correct choice values (Bottom panel) were also higher in the PHACR group than in the SALR and NTRR groups. ANOVA showed a significant effect of group $\left(\mathrm{F}_{2,15}=16.93 ; p<0.001\right)$, which was related with the higher accuracy of choice in PHACR than in SALR and NTRR groups in both the final training and the test $(p<0.05)$.

Figure 3 presents in Panel (a) (left) a schematic representation of a frontal view of one hemisphere of the

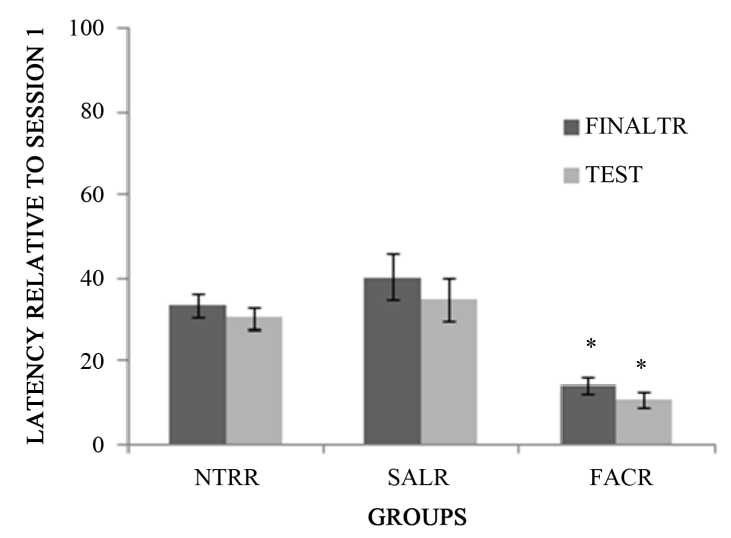

(a)

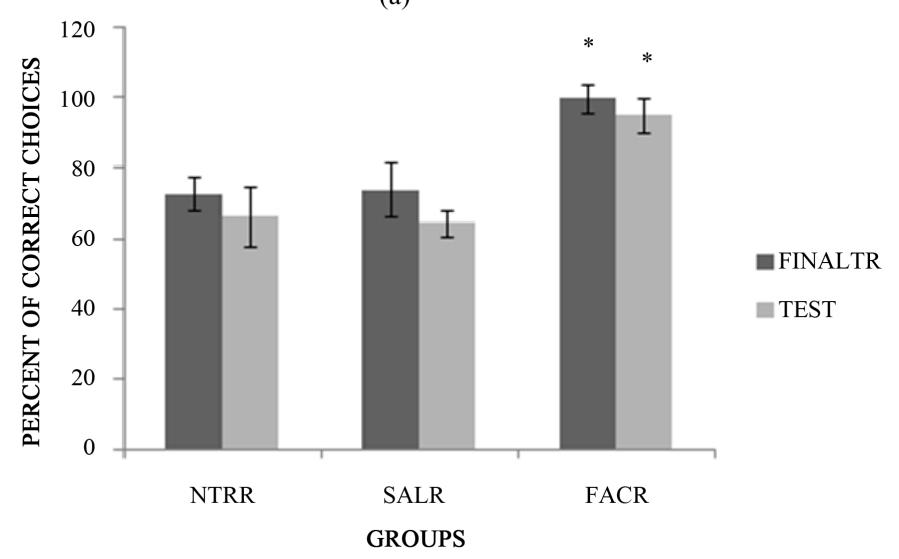

(b)

Figure 2. (a) Mean percent values ( \pm s.e.m) of the latency (sec) of the feeder choice response in the $7^{\text {th }}$ training session (final training) and in the testing session (test). Each value was calculated relative to the $1^{\text {st }}$ session of training; (b) Mean values of correct choices index in the final training and in the test. *Significantly different from the final training and to the test of the SALR and NTRR groups (Tukey-Kramer test, $p<0.05$ ). 
(a)

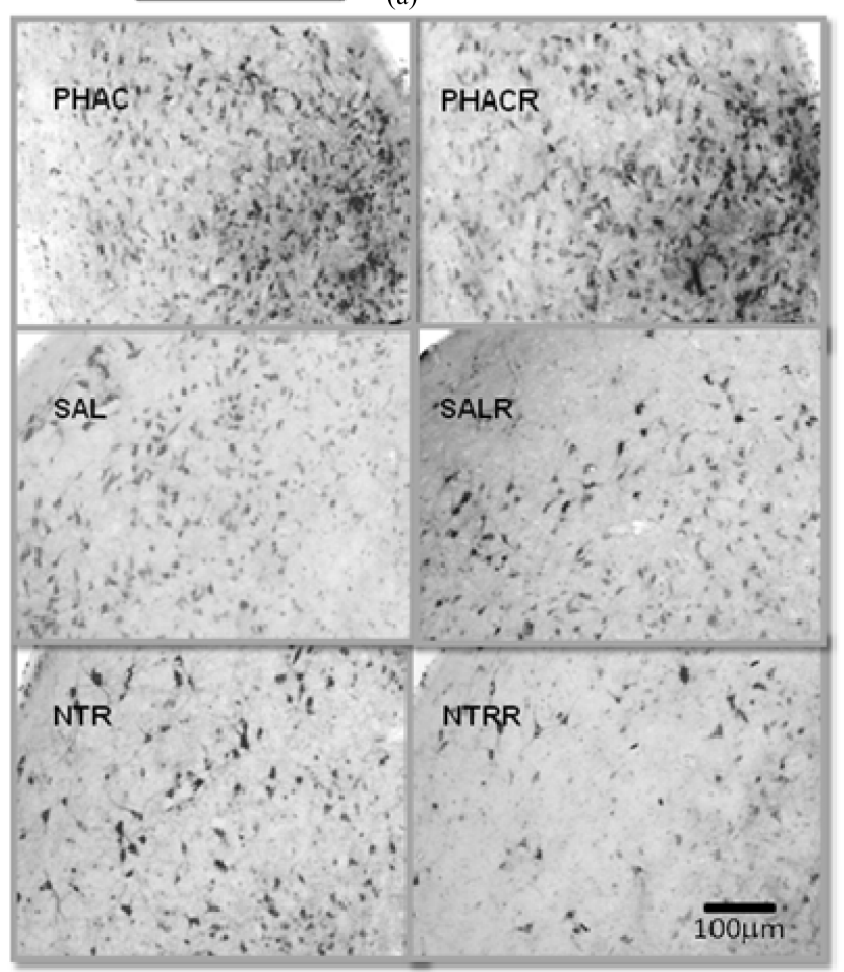

(b)

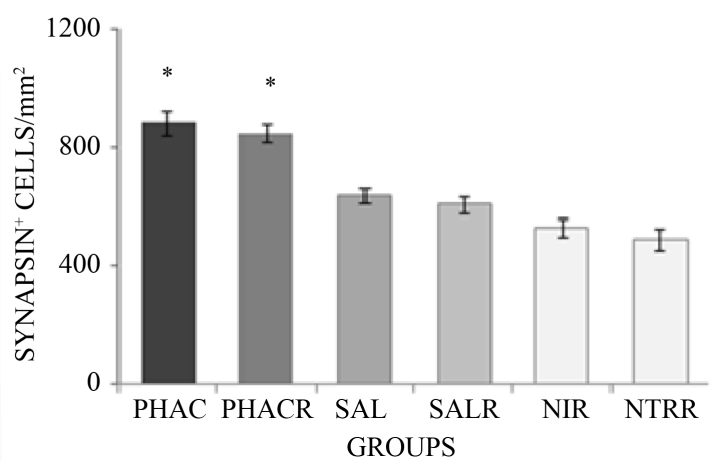

(c)

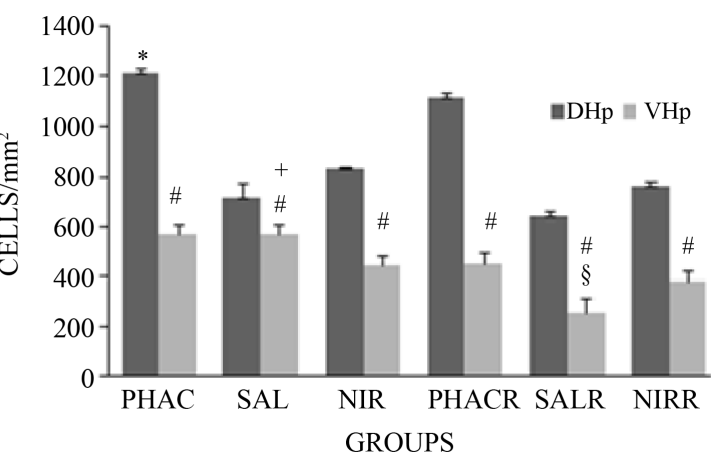

(d)

Figure 3. (a) Schematic representation of one frontal section of the brain of the pigeon and one digital image of the hippocampi with indication of dorsal $(\mathrm{HpD})$ and ventral $(\mathrm{HpV})$ regions. Hp: hippocampus; N: nidopallium; A: arcopallium; (b): Digitized images (frontal sections; AP 6.75) of the dorsal hippocampus region of pigeons showing the pattern of immunoreactive labeling of Synapsin I. Scale bar $=100 \mu \mathrm{m}$. PHAC: phaclofen treatment; PHACR: phaclofen treatment and test of memory persistence; SAL: saline treatment; SALR: saline treatment and test of memory persistence; NTR: no-treatment; NTRR: no-treatment and test of memory persistence; (c) Average density of Synapsin I-positive cells in the hippocampus of pigeons trained in food location (PHAC, SAL and NTR) and tested for memory persistence (PHACR, SALR and NTRR). "Significantly different from SAL, NTR, SALR and NTRR groups (Tukey-Kramer, $p<0.05$ ); (d) Average density of Synapsin I-positive cells for the regions $\mathrm{HpD}$ and $\mathrm{HpV}$ of the hippocampus of pigeons in each group. *Significant difference from SAL, NTR, SALR and NTRR groups; " Different from DHp; ${ }^{\S}$ Different from all the other groups; ${ }^{+}$Different from SALR, NTR and NTRR (Tukey-Kramer, $p<0.05$ ).

pigeon's brain [10], and (right), a digital image of the hippocampus with indication of the dorsal (DHp) and ventral (VHp) regions of the hippocampus, which were used for the cell counting analysis. Panel (b) presents digitized images of Synapsin I-positive cells, which were obtained from frontal, unilateral images of the dorsal region of the hippocampus sections around the level AP 6.75 [10], for birds of the groups PHAC, SAL, NTR, with the immunohistochemical analysis conducted after the $7^{\text {th }}$ session of training and in the PHACR, SALR and NTRR groups, with the analysis conducted after the test. The immunoreactivity for Synapsin I, characterized by marking of the neuronal cytoskeleton, was more intense in the PHAC and PHACR groups than in the other groups. In Panel (c), we find the values of average density of Synapsin I-positive cells counting in the hippocampus of pigeons for each of the groups-PHAC, SAL, NTR, PHACR, SALR and NTRR groups. ANOVA indicated a significant difference between groups $\left(\mathrm{F}_{5,24}=120.9, p<0.0001\right)$. The groups treated with phaclofenPHAC and PHACR, were significantly different from the groups treated with saline-SAL and SALR and from the non-treated groups-NTR and NTRR $(p<0.05)$. No significant differences were found between PHAC and 
PHACR groups $(p>0.05)$. Panel $(d)$ shows the mean density of Synapsin I-positive cells found in DHp and VHp areas of the hippocampus of pigeons of each group. ANOVA indicated that the average density of Synapsin I-positive cells in DHp and VHp had a significant difference between groups $\left(\mathrm{F}_{5,24}=38.27, p<0.001\right)$, between regions $\left(\mathrm{F}_{1,24}=498.12, p<0.0001\right)$ and a significant interaction between group $\times$ region $\left(\mathrm{F}_{5,5}=16.66, p\right.$ $<0.001$ ). The values obtained with Synapsin I-positive cells counting in the DHp region in the groups PHAC and PHACR differed significantly from their VHp region and from both DHp and VHp regions of the SAL, SALR, NTR AND NTRR groups $(p<0.05)$. Significant differences were also observed in the VHp region of the SAL Group and NTR and NTRR groups $(p<0.05)$. The values in the VHp region of SALR Group were significantly different from those of all the other groups $(p<0.05)$.

\section{Discussion}

This study indicated that the post-training administration of the $\mathrm{GABA}_{\mathrm{B}}$ receptor blocker, phaclofen, resulted in significant decrease in the latency of choice response and also in a significant increase in the rate of correct choice responses across the sessions of training in a task of food location by pigeons. The performance of PHAC pigeons support the consideration of facilitation of food location memory by the blockade of $\mathrm{GABA}_{B}$ receptor, although training has been efficient for learning and memory of the spatial task by the three groups of pigeons, independently of treatment condition. This enhancement is evidenced by the robust decrease in the latency of choice and the increased accuracy rate that were seen early in the second training session. The curves of latency and correct response of the PHAC group indicate that pigeons treated with phaclofen showed faster performance and higher accuracy across the sessions than the SAL and NTR pigeons. Our study agrees with previous studies showing spatial learning in food location tasks by pigeons [19] [20] [22] and by Zebra finches [2] [23]. Furthermore, our data showing the enhancing effect of $\mathrm{GABA}_{\mathrm{B}}$ blockade on the performance in food location task confirm, for pigeons, the literature on enhancement of behavioral and cognitive processes after the use of $\mathrm{GABA}_{\mathrm{B}}$ receptor antagonist in mammals [10]-[12] [27] [28]. In addition, the behavioral data suggest that the blockade of $\mathrm{GABA}_{\mathrm{B}}$ receptors interfered both with processes of consolidation and with the persistence of the food location memory. The enhanced consolidation of the food location memory could be evidenced by the group differences in performance already seen in the second training session. Furthermore, 7 days after the last training session, during the test of memory persistence, birds treated with phaclofen performed better than SALR and NTRR birds, thus, suggesting that the treatment with phaclofen also affected processes that are involved in the persistence of food location memory.

These data may suggest that the blockade of $\mathrm{GABA}_{\mathrm{B}}$ receptor interfered with cellular mechanisms that are triggered by the experience of spatial training, which eventually support both the formation and persistence of memory. Phaclofen binding to specific sites on the $\mathrm{GABA}_{\mathrm{B}}$ receptor, blocking its activation by GABA, induces alterations in the molecular cascade normally activated by $G_{A B A}$ receptor (Figure 4). Also, the presynaptic function of $\mathrm{GABA}_{\mathrm{B}}$ autoreceptors, which may inhibit the GABA release by pre-synaptic neurons, could also be altered [4] [5]. So, the result could be decreased neuronal inhibition and consequent increased neuronal excitation. Therefore, a decrease in GABAergic inhibition could alter intracellular signaling pathways in neurons of the hippocampus which are essential for the formation of spatial memory. This is in line with rodents and birds studies that demonstrated the fundamental involvement of NMDA receptors with memory processes, regulating both the sequence of pre- and post-synaptic events involved with long-lasting cellular changes and the increased expression of proteins that underlies the long-term memory. Consequently, decreases in neuronal inhibition due to the blockade of GABAergic action can potentiate these mechanisms. Accordingly, the administration of $\mathrm{GABA}_{\mathrm{B}}$ antagonist can increase synaptic long-term potentiation (LTP), effect that may depend on the stimulation frequency used for LTP induction [5]. Moreover, it is also worth to note that Cullen et al. [28] suggest that pre-synaptic inhibition via $\mathrm{GABA}_{B}$ receptors may play a key role preserving the precision of a particular memory.

The enhancement of memory of food location, both in PHAC and PHACR birds when compared to the control groups, was positively related with up regulation of Synapsin I in the hippocampus. These data suggest that molecular mechanisms underlying memory were altered by the blockade of $\mathrm{GABA}_{\mathrm{B}}$ receptor. The regional differences in Synapsin I-positive cells counting may be related with the complex neurochemical profile of both dorsal and ventral regions of the avian hippocampus [29] [30]. In addition, the DHp receives sensorial information arriving to the hippocampus and, also, has efferent projections of the hippocampus to other pallidal areas [31]. 


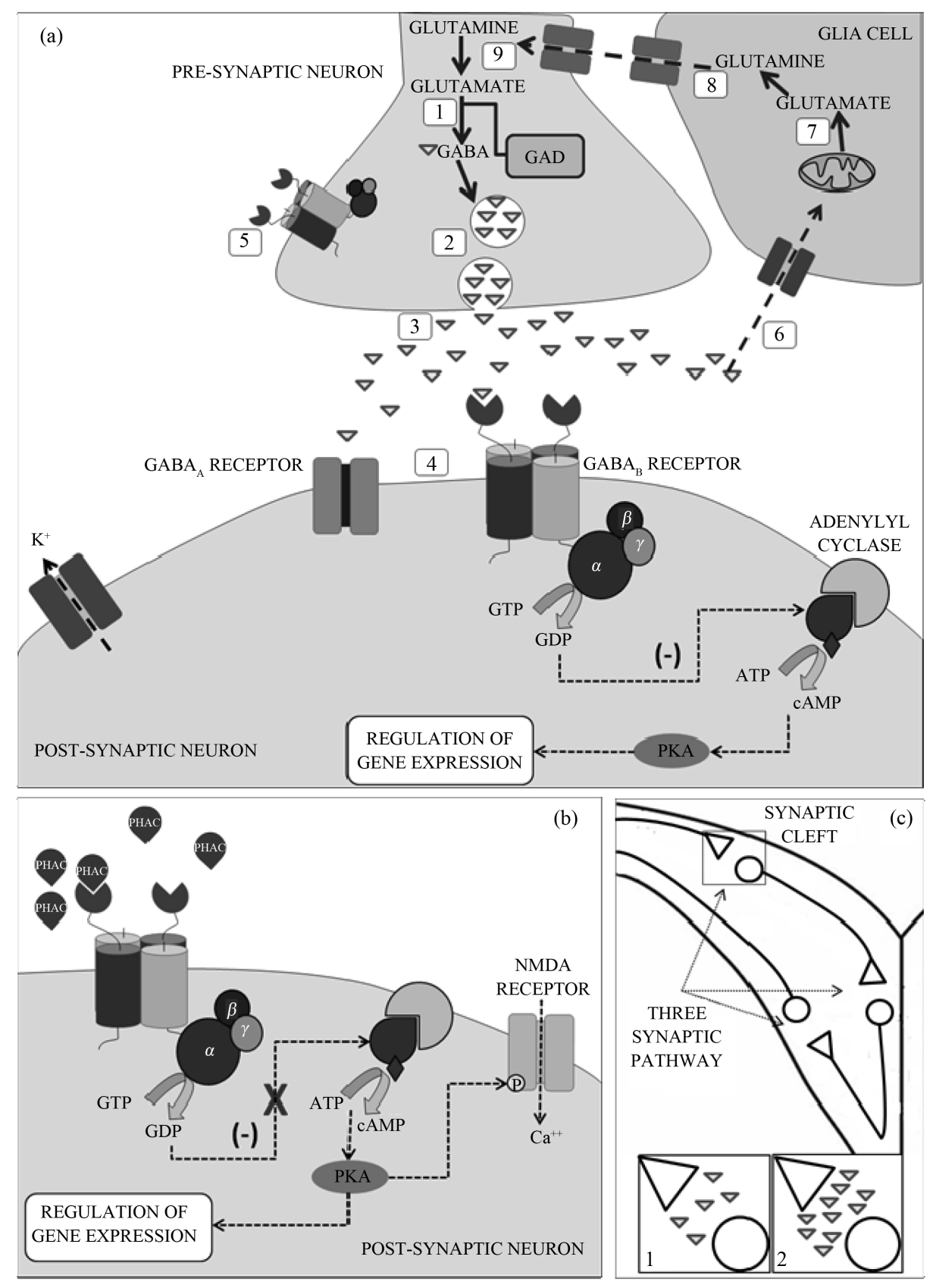

Figure 4. (a) Synthesis of $\gamma$-aminobutyric acid (GABA) from glutamate (catalyzed by L-glutamate decarboxylase (GAD)) (1) after the synthesis, GABA neurotransmitter is stored in vesicles (2) later release into the synaptic cleft by exocytosis (3) and connecting the ionotropic receptors $\left(\mathrm{GABA}_{\mathrm{A}}\right)$ and metabotropic $\left(\mathrm{GABA}_{\mathrm{B}}\right)$, both located in the postsynaptic neuron (4) and presynaptic neurons (5), similarly, the GABA is transported to glia cells (6), occurring transamination of GABA to $\alpha$-ketoglutarate, thus regenerating glutamate (7), which in turn is converted into glutamine by the enzyme glutamine synthetase, and this in turn is transported to the presynaptic neuron (8) suffering glutaminase activity of the enzyme is synthesized in glutamate again, starting a new cycle (9); (b) The phaclofen molecules bind to specific site of the GABA receptor; this causes blockage of inhibitory signaling pathway and consequent increased gene activity; (c) In the hippocampus, there is a three synaptic pathway, when $G_{B B} A_{B}$ receptors are activated control the release of neurotransmitters into the synaptic cleft (C1) in the presence of phaclofen, this control does not occur, thereby increasing the amount of available neurotransmitter in the synaptic cleft (C2) remaining longer stimulation. Figure 4(a) adapted from [34]. 
Other studies showed increased Synapsin I immunorreaction after learning and memory formation [14] [16] [18] [32]. However, decreases in the expression of Synapsin I in the hippocampus of rats have also been reported after complete learning of an operant task [8]. Although this study has focused plastic changes due to learning and to the blockade of $\mathrm{GABA}_{\mathrm{B}}$ only in the hippocampus, we cannot rule out the possible action of phaclofen in other neural structures known to participate in spatial learning and memory processes. The systemic administration of phaclofen may have altered synaptic activity within a neural network where the hippocampus, both in mammals and birds, has a central role in spatial cognition [2] [6] [26]. In fact, a wide distribution of glutamate and GABA receptors is found across the regions of hippocampal formation [30] [33].

\section{Conclusions}

Taken together our data, we might say that the present study contributes to the knowledge about the role of $\mathrm{GABA}_{\mathrm{B}}$ receptors in the modulation of behavioral and cognitive processes, extending to birds' previous observations reported for rodents.

Furthermore, the increased expression of Synapsin I in the hippocampus, which is related with $\mathrm{GABA}_{\mathrm{B}}$ receptors blockade, indicates that $\mathrm{GABA}_{\mathrm{B}}$ receptors can also regulate key molecular events in the hippocampus during the formation and persistence of spatial memory. In addition, this study, along with a growing body of recent studies [2] [15] [24], indicates that birds, particularly the pigeon, are interesting experimental models for the study of neural and behavioral aspects of learning and memory, allowing the analysis of processes and mechanisms that are conservative among mammals and birds.

\section{Acknowledgements}

These studies were supported by FAPESP (2010/016693-1) and CNPq (304933-2012-0). The authors are indebted to W. L. Gomes for his support in the routine animal care.

\section{References}

[1] Eichenbaum, H., Otto, T. and Cohen, N.J. (1992) The Hippocampus-What Does It Do? Behavioral and Neural Biology, 7, 2-36. http://dx.doi.org/10.1016/0163-1047(92)90724-I

[2] Mayer, U., Watanabe, S. and Bischof, H.J. (2013) Spatial Memory and the Avian Hippocampus: Research in Zebra Finches. Journal of Physiology, 107, 2-12.

[3] Kandel, E.R. (2001) The Molecular Biology of Memory Storage: A Dialogue between Genes and Synapses. Science, 294, 1030-1038. http://dx.doi.org/10.1126/science.1067020

[4] Bowery, N.G. (2010) Historical Perspective and Emergence of the GABAB Receptor. Advances in Pharmacology, 58, 1-18. http://dx.doi.org/10.1016/S1054-3589(10)58001-3

[5] Mott, D.D. and Lewis, D.V. (1994) The Pharmacology and Function of Central GABAB Receptors. International Review of Neurobiology, 36, 97-223. http://dx.doi.org/10.1016/S0074-7742(08)60304-9

[6] Karten, H.J. and Hodos, W. (1967) A Stereotaxic Atlas of the Brain of the Pigeon (Columba livia). The Johns Hophins Press, Baltimore.

[7] Castellano, C., Cabib, S. and Puglisi-Allegra, S. (1996) Psychopharmacology of Memory Modulation: Evidence for Multiple Interaction among Neurotransmitters and Hormones. Behavioural Brain Research, 77, 1-21. http://dx.doi.org/10.1016/0166-4328(96)00200-8

[8] Rapanelli, M., Frick, L.R. and Zanutto, B.S. (2009) Differential Gene Expression in the Rat Hippocampus during Learning of an Operant Conditioning Task. Neuroscience, 163, 1031-1038. http://dx.doi.org/10.1016/j.neuroscience.2009.07.037

[9] Möhler, H., Fritschy, J.M., Crestani, F., Hensch, T. and Rudolph, U. (2004) Specific GABA(A) Circuits in Brain Development and Therapy. Biochemical Pharmacology, 68, 1685-1690. http://dx.doi.org/10.1016/j.bcp.2004.07.025

[10] Mondadori, C., Buerki, H., Borkowski, J., Radeke, E., Ducret, T. and Glatt, A. (1992) CGS 5649 B, a New Compound, Reverses Age-Related Cognitive Dysfunctions in Rats. Behavioral and Neural Biology, 57, 149-156. http://dx.doi.org/10.1016/0163-1047(92)90653-L

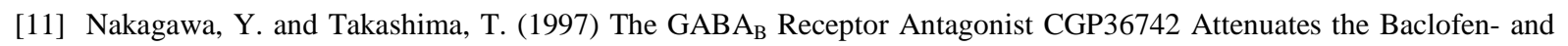
Scopolamine-Induced Deficit in Morris Water Maze Task in Rats. Brain Research, 766, 101-106. http://dx.doi.org/10.1016/S0006-8993(97)00529-5

[12] Sunyer, B., Shim, K.S., An, G., Höger, H. and Lubec, G. (2009) Hippocampal Levels of Phosphorylated Protein Ki- 
nase A (Phosphor-S96) Are Linked to Spatial Memory Enhancement by SGS742. Hippocampus, 19, 90-98. http://dx.doi.org/10.1002/hipo.20484

[13] Froestl, W., Gallagher, M., Jenkins, H., Madrid, A., Melcher, T., Teichman, S., Mondadori, C.G. and Pearlman, R. (2004) SGS742: The First GABA ${ }_{B}$ Receptor Antagonist in Clinical Trials. Biochemical Pharmacology, 68, 1479-1487. http://dx.doi.org/10.1016/j.bcp.2004.07.030

[14] Gómez-Pinilla, F., So, V. and Kesslak, J.P. (2001) Spatial Learning Induces Neurotrophin Receptor and Synapsin I in the Hippocampus. Brain Research, 904, 13-19. http://dx.doi.org/10.1016/S0006-8993(01)02394-0

[15] Güntürkün, O. (2012) The Convergent Evolution of Neural Substrates for Cognition. Psychological Research, 76, $212-$ 219. http://dx.doi.org/10.1007/s00426-011-0377-9

[16] Corradi, A., Zanardi, A., Giacomini, C., Onofri, F., Valtorta, F., Zoli, M. and Benfenati, F. (2008) Synapsin-I- and Synapsin-II-Null Mice Display an Increased Age-Dependent Cognitive Impairment. Journal of Cell Science, 121, 3042-3051. http://dx.doi.org/10.1242/jcs.035063

[17] Jovanovic, J.N., Czernik, A.J., Fienberg, A.A., Greengard, P. and Sihra, T.S. (2000) Synapsins as Mediators of BDNFEnhanced Neurotransmitter Release. Nature Neuroscience, 3, 323-329. http://dx.doi.org/10.1038/73888

[18] Melloni Jr., R.H., Apostolides, P.J., Hamos, J.E. and De Gennaro, L.J. (1994) Dynamics of Synapsin I Gene Expression during the Establishment and Restoration of Functional Synapses in the Rat Hippocampus. Neuroscience, 58, 683703. http://dx.doi.org/10.1016/0306-4522(94)90448-0

[19] Amaral-Toma, M. and Ferrari, E.A.M. (2004) Effects of Hippocampal Lesions in a Food Location Task in Pigeons. Behavioral Brain Research, 148, 21-34.

[20] Kahn, M.C. and Bingman, V.P. (2009) Avian Hippocampal Role in Space and Content Memory. European Journal of Neuroscience, 30, 1900-1908. http://dx.doi.org/10.1111/j.1460-9568.2009.06979.x

[21] Colombo, M. and Broadbent, N. (2000) Is the Avian Hippocampus a Functional Homologue of the Mammalian Hippocampus? Neuroscience \& Biobehavioral Reviews, 24, 465-484. http://dx.doi.org/10.1016/S0149-7634(00)00016-6

[22] Fremouw, T., Jackson-Smith, P. and Kesner, R.P. (1997) Impaired Place Learning and Unimpaired Cue Learning in Hippocampal-Lesioned Pigeons. Behavioral Neuroscience, 11, 963-975. http://dx.doi.org/10.1037/0735-7044.111.5.955

[23] Watanabe, S. and Bischof, H.J. (2012) Spatial Cognition of Zebra Finches in a Morris-Maze Analogue Apparatus. International Journal of Comparative Psychology, 25, 276-284.

[24] Faria, R.S., Sartori, C.R., Canova, F. and Ferrari, E.A.M. (2013) Classical Aversive Conditioning Induces Increased Expression of Mature-BDNF in the Hippocampus and Amygdala of Pigeons. Neuroscience, 255, 122-133. http://dx.doi.org/10.1016/j.neuroscience.2013.09.054

[25] Brito, I., Britto, L.R.G. and Ferrari, E.A.M. (2006) Classical Tone-Shock Conditioning Induces Zenk Expression in the Pigeon (Columba livia) Hippocampus. Behavioral Neuroscience, 120, 353-361. http://dx.doi.org/10.1037/0735-7044.120.2.353

[26] Atoji, Y. and Wild, J.M. (2006) Anatomy of the Avian Hippocampal Formation. Reviews in the Neurosciences, 17, 315. http://dx.doi.org/10.1515/REVNEURO.2006.17.1-2.3

[27] John, J.P., Sunyer, B., Höger, H., Pollak, A. and Lubec, G. (2009) Hippocampal Synapsin Isoform Levels Are Linked to Spatial Memory Enhancement by SGS742. Hippocampus, 19, 731-778. http://dx.doi.org/10.1002/hipo.20553

[28] Cullen, P.K., Dulka, B.N., Ortiz, S., Riccio, D.C. and Jasnow, A.M. (2014) GABA-Mediated Presynaptic Inhibition Is Required for Precision of Long-Term Memory. Learning \& Memory, 21, 180-184. http://dx.doi.org/10.1101/lm.032961.113

[29] Erichsen, J.T., Bingman, V.P. and Krebs, J.R. (1991) The Distribution of Neuropeptides in the Dorsomedial Telencephalon of the Pigeon (Columba livia): A Basis for Regional Subdivisions. Journal of Comparative Neurology, 314, 478-492. http://dx.doi.org/10.1002/cne.903140306

[30] Herold, C., Bingman, V.P., Ströckens, F., Letzner, S., Sauvage, M., Palomero-Gallagher, N., Zilles, K. and Güntürkün, O. (2014) Distribution of Neurotransmitter Receptors and Zinc in the Pigeon (Columba livia) Hippocampal Formation: A Basis for Further Comparison with the Mammalian Hippocampus. Journal of Comparative Neurology, 522, 25532575. http://dx.doi.org/10.1002/cne.23549

[31] Kahn, M.C., Hough II, G.E., Eyck, G.R.T. and Bingman, V.P. (2003) Internal Connectivity of the Homing Pigeons (Columba livia) Hippocampal Formation: An Anterograde and Retrograde Tracer Study. Journal of Comparative Neurology, 459, 127-141. http://dx.doi.org/10.1002/cne.10601

[32] Kushner, S.A., Elgersma, Y., Murphy, G.G., Jaarsma, D., van Woerden, G.M., Hojjati, M.R., Cui, Y., Le Boutillier, J.C., Marrone, D.F., Choi, E.S., De Zeeuw, C.I., Petit, T.L., Pozzo-Miller, L. and Silva, A.J. (2005) Modulation of Presynaptic Plasticity and Learning by the H-Ras/Extracellular Signal-Regulated Kinase/Synapsin I Signaling Pathway. The Journal of Neuroscience, 25, 9721-9734. http://dx.doi.org/10.1523/JNEUROSCI.2836-05.2005 
[33] Rosinha, M.U., Ferrari, E.A. and Toledo, C.A. (2009) Immunohistochemical Distribution of AMPA-Type Label in the Pigeon (C. livia) Hippocampus. Neuroscience, 159, 438-450. http://dx.doi.org/10.1016/j.neuroscience.2009.01.010

[34] Hyland, N.P. and Cryan, J.F. (2010) A Gut Feeling about GABA: Focus on GABAB Receptors. Frontiers in Pharmacology, 1, 124. 
Scientific Research Publishing (SCIRP) is one of the largest Open Access journal publishers. It is currently publishing more than 200 open access, online, peer-reviewed journals covering a wide range of academic disciplines. SCIRP serves the worldwide academic communities and contributes to the progress and application of science with its publication.

Other selected journals from SCIRP are listed as below. Submit your manuscript to us via either submit@scirp.org or Online Submission Portal.
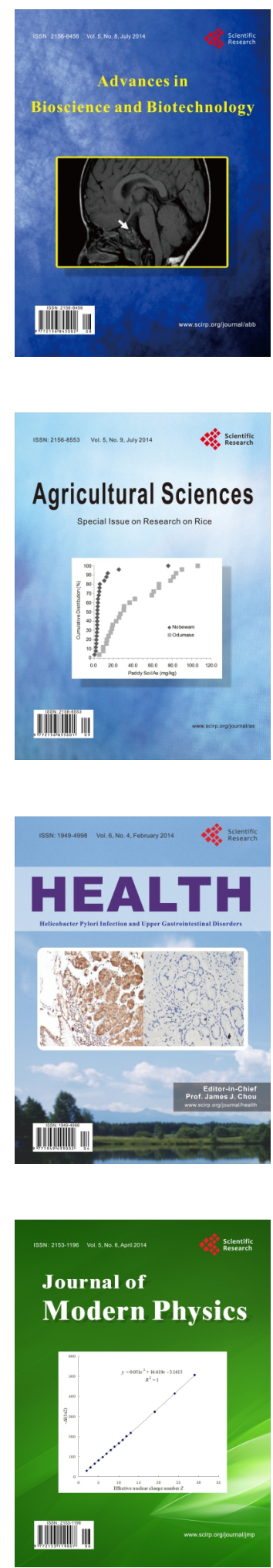
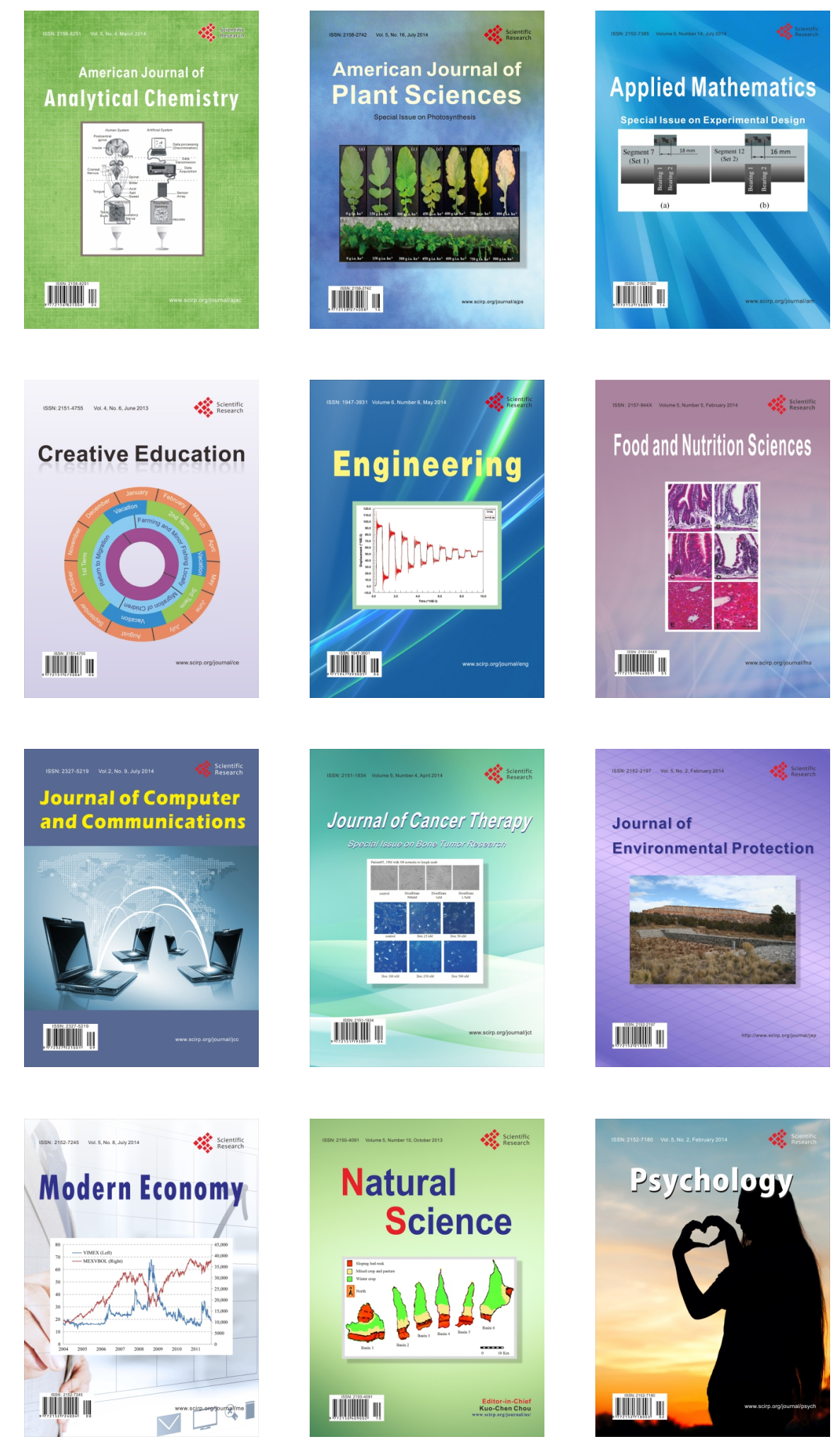